\title{
WORM - A NEW OPEN ROAD LINE SOURCE MODEL FOR LOW WIND SPEED CONDITIONS
}

\author{
Sam-Erik Walker \\ Norwegian Institute for Air Research (NILU), Kjeller, Norway
}

\begin{abstract}
Emission from road traffic constitutes one of the most important sources of air pollution in urban areas. This paper describes a newly developed air pollution dispersion model for open roads and highways called WORM (Weak Wind Open Road Model), and give some results using this model during low wind speed and (strongly) stable atmospheric conditions at Nordbysletta in Norway, during a 3-4 months period in the winter/spring of 2002
\end{abstract}

Key words: open road; highway; integrated Gaussian; low wind speed; stable conditions; traffic produced turbulence.

\section{INTRODUCTION}

Emission from road traffic constitutes one of the most important sources of air pollution in urban areas. Despite recent improvements in air quality regulation, and new technology for reduction of vehicle emissions, increases in the number of vehicles often lead to increased pollution levels and impact on health and well-being of the population in affected areas. In the Nordic countries, the highest concentrations (hourly average or daily mean values) during a year typically occur during winter-time inversion episodes with low wind speeds $\left(<1-2 \mathrm{~ms}^{-1}\right)$. Pollutant concentrations near roads can be estimated on an hourly basis using appropriate dispersion modelling technique. This paper describes a newly developed air pollution dispersion model for open roads and highways called WORM (Weak Wind Open Road Model), and give some results using this model during low wind speed and (strongly) stable atmospheric conditions at Nordbysletta in Norway during a 3-4 months period in the winter/spring of 2002.

\section{MODEL DESCRIPTION}

The WORM model is an integrated Gaussian puff/plume model for calculating hourly average concentrations from open roads and highways in a set of arbitrary receptor points. The model is thus similar to other well-known integrated Gaussian line source models, such as e.g., the CAR-FMI model, or the HIWAY II or CALINE-4 models etc. In the development of the WORM model, however, we put special emphasis on attempting to model well concentrations during Nordic winter-time, strongly stable, low-wind speed conditions, yet still within the framework of a Gaussian model. We also put emphasis on creating a model that can run reasonably fast, making it possible to perform model calculations on an hourly basis for (possibly) thousands of receptor points and line sources within an urban area, within a reasonable time (seconds to minutes) on a standard stationary or laptop PC. In addition, the model has been developed specifically with the aim of being able to produce concentration values with some calibrated quantification of uncertainties, using sensible input data perturbations and model ensemble runs, as described in (Walker, S.E., 2007), but this will not be described further here.

\section{Modular coding}

The WORM model is coded in FORTRAN 95/2003 using modern principles of Object Oriented Programming (OOP). The program code is divided into several independent modules, where each module contains subroutines and functions covering a specific set of tasks. In addition new data type variables (class objects in FORTRAN) are used to define sets of data which naturally belongs together, such as e.g., emission data, meteorology, concentration results etc. For the current software development, the Intel Visual Fortran compiler version 10.1 has been used together with the Microsoft Visual Studio 2005 environment, which we have found to be a very good environment for developing and debugging code.

The current version of the WORM model consists of the following system components (modules):

- An emission pre-processor (1src_m.for)

- A background concentration data pre-processor (conc_m.for)

- A pre-processor for meteorological data (mete_m.for)

- An integrated Gaussian puff/plume type of dispersion model (worm_m.for)

- A module containing the numerical integration methods (quad_m.for)

\section{Emission and background concentration data pre-processing}

The emission pre-processor generates hourly emission data $\left(\mathrm{Q}\right.$ in $\left.\mathrm{gm}^{-1} \mathrm{~s}^{-1}\right)$ for each lane of the roadway based on traffic data from the NILU AirQUIS system (AirQUIS, 2005). The background concentration pre-processor generates hourly average background concentrations for the road, based on using nearby (upwind) background stations, or urban/regional scale models, also provided by the AirQUIS system. Background concentrations are generally added to the WORM model concentrations to make model output comparable with local (roadside) air quality observations. Currently the WORM model is only run for inert species, such as e.g., $\mathrm{NO}_{\mathrm{x}}$. Photochemistry will be added later. 


\section{Meteorological pre-processing}

A new meteorological pre-processor (WMPP) has been constructed as part of the WORM model development. The pre-processor applies the profile method using hourly observations of wind speed at one height (usually $10 \mathrm{~m}$ ) and temperature difference between two heights (usually 10 and $2 \mathrm{~m}$ ) in order to calculate other derived meteorological parameters. Given these data, and an estimate of the momentum surface roughness $\mathrm{z}_{0 \mathrm{~m}}$, it calculates friction velocity $\left(u_{*}\right)$, temperature scale $\left(\theta_{*}\right)$ and inverse Obukhov length scale $\left(\mathrm{L}^{-1}\right)$ according to Monin-Obukhov similarity theory. The set of similarity functions suggested by (Högström, 1996) is used to calculate vertical profiles of temperature and wind. The pre-processor then calculates mixing height $\left(H_{m i x}\right)$, horizontal and vertical diffusivities $\left(\sigma_{u}, \sigma_{v}, \sigma_{w}\right)$, and Lagrangian time scales $\left(T_{L x}, T_{L y}, T_{L z}\right)$. Several different schemes can be chosen for these calculations, including some recommended schemes from COST 710 (Fisher et al., 1998). Minimum values can be defined for some of the meteorological parameters such as the effective wind speed, Obukhov length, mixing height and horizontal and vertical diffusivities.

\section{Integrated Gaussian puff/plume formulation}

The WORM model calculates hourly average concentrations in one or more receptor points by integrating a Gaussian puff or plume function along each lane of the road, adding up the contribution from each lane. The Gaussian plume function with dispersion parameters $\sigma_{y}$ and $\sigma_{z}$ is used whenever the slanted plume approximation $\left(\sigma_{x} / x<<1\right)$ is valid, but the model switches to a puff formulation, with dispersion parameter $\sigma_{x}=\sigma_{y}$ along the downwind x-axis, in low wind speed conditions, when the slanted plume approximation is no longer valid (typically for $U_{\text {eff }}<1 \mathrm{~ms}^{-1}$ ). Thus, the concentration in a receptor point $r=\left(\mathrm{x}_{\mathrm{r}}, \mathrm{y}_{\mathrm{r}}, \mathrm{z}_{\mathrm{r}}\right)$ is generally calculated by:

$$
\begin{gathered}
C_{r}=\int_{s=0}^{S} \int_{t=0}^{T} \frac{Q}{(2 \pi)^{3 / 2} \cdot \sigma_{x}(t) \cdot \sigma_{y}(t) \cdot \sigma_{z}(t)} \cdot \exp \left(-\frac{\left(x_{r}(s)-U_{e f f} \cdot t\right)^{2}}{2 \sigma_{x}^{2}(t)}\right) \cdot \exp \left(-\frac{y_{r}^{2}(s)}{2 \sigma_{y}^{2}(t)}\right) . \\
\left\{\exp \left(-\frac{\left(z_{r}-H_{e f f}\right)^{2}}{2 \sigma_{z}^{2}(t)}\right)+\exp \left(-\frac{\left(z_{r}+H_{e f f}\right)^{2}}{2 \sigma_{z}^{2}(t)}\right)\right\} d s d t
\end{gathered}
$$

where $Q$ is the emission intensity $\left(\mathrm{gm}^{-1} \mathrm{~s}^{-1}\right), U_{\text {eff }}$ is the plume effective wind speed $\left(\mathrm{ms}^{-1}\right), H_{\text {eff }}$ is the plume effective height above ground $(\mathrm{m})$, and where the coordinates of the receptor point and dispersion parameters in the integrand generally depends on the position $\mathrm{s}$ on the road, and time $t$ since release. The concentration is obtained by integrating all the infinitesimal puffs over the length $S(\mathrm{~m})$ of the road, during the current hour (T=3600 s). All integrations (for puffs and plumes) are generally performed using fast approximations, employing Gaussian error-functions (erfs), except for situations when the wind is more along the road where a highly accurate Gaussian quadrature scheme (Patterson's QUAD) is employed (Kythe and Schäferkotter, 2005).

\section{Ambient atmospheric turbulence}

In previous beta releases of the WORM model, the dispersion parameters $\sigma_{X}=\sigma_{y}$ and $\sigma_{z}$ were calculated using the same formulation as in the CAR-FMI model (Härkönen et al., 1996), with horizontal and vertical turbulence intensities $\sigma_{V}$ and $\sigma_{W}$ calculated based on recommended expressions from COST 710 (Fisher et al., 1998). In the current release of the WORM model, horizontal and vertical dispersion parameters can also be calculated using the same formulation as suggested in the OML Research Version model (Olesen et al., 2007, chapters 5.2-3):

$$
\begin{aligned}
& \sigma_{\mathrm{y}}^{2}=\sigma_{\mathrm{y}, \text { Atm }}^{2}+\sigma_{\mathrm{y}, \text { TPT }}^{2} \\
& \sigma_{\mathrm{z}}^{2}=\sigma_{\mathrm{z}, \mathrm{Atm}}^{2}+\sigma_{\mathrm{z}, \text { TPT }}^{2}
\end{aligned}
$$

where $\sigma_{y, A t m}$ and $\sigma_{z, \text { Atm }}$ defines growth of the puff or plume due to ambient atmospheric turbulence divided into mechanical and convective parts and where the horizontal part in addition includes the effect of plume meandering. The quantities $\sigma_{y, T P T}$ and $\sigma_{Z, T P T}$ describes growth of the puff or plume due to traffic produced turbulence (TPT) as defined in the next section.

\section{Traffic produced turbulence (TPT)}

For roadway models it is important to include traffic produced turbulence (TPT) generated by the moving vehicles, especially in situations with low wind speeds (Berkowicz et al., 2007). In the previous beta release of the WORM model (Berger et al., 2008), $\sigma_{x, T P T}=\sigma_{y, T P T}$ and $\sigma_{z, T P T}$ was calculated using the same semi-empirical equation for traffic-originated turbulence as used in the CAR-FMI model (Härkönen et al., 1996). This defines $\sigma_{y, T P T}$ and $\sigma_{z, T P T}$ simply as constant additive terms $\sigma_{y 0}$ and $\sigma_{z 0}$ in Equation (2). Previous runs with the WORM model employing the CAR-FMI dispersion scheme has shown that this is not adequate, especially for (strongly) stable atmospheric conditions with very low wind speeds $\left(U_{10 \mathrm{~m}}<0.5 \mathrm{~ms}^{-1}\right)$, as is the case at Nordbysletta, giving model concentrations much higher than observed.

In the new release of the WORM model we have therefore included a new formulation for TPT based on the same scheme as used in the OML Highway model (Berkowicz et al., 2007). In this formulation, $\sigma_{y, T P T}=0$, while $\sigma_{z, T P T}$ is calculated as follows:

$$
\sigma_{z, \text { TPT }}=\sigma_{z 0}+u_{\mathrm{TPT}} \cdot \tau \cdot(1-\exp (-\mathrm{t} / \tau))
$$


where $\sigma_{z O}$ is the initial value of $\sigma_{z, T P T}$ close to the roadway, $\mathrm{u}_{\mathrm{TPT}}=\sqrt{\mathrm{E}}$ where $E$ is the turbulent kinetic energy (TKE) calculated from the moving vehicles, $t$ is the effective transport time from the road to the receptor point $\left(t=x / U_{\text {eff }}\right)$, and where $\tau$ is a time constant as defined below. Here $E$ is calculated as:

$$
\mathrm{E}=\alpha \cdot\left(\mathrm{N}_{\mathrm{L}} \cdot \mathrm{A}_{\mathrm{L}} \cdot \mathrm{V}_{\mathrm{L}}+\mathrm{N}_{\mathrm{H}} \cdot \mathrm{A}_{\mathrm{H}} \cdot \mathrm{V}_{\mathrm{H}}\right) / \mathrm{W}
$$

where $N_{X}$ is the number of vehicles per second, $V_{X}$ is the vehicles average speed, and $A_{X}$ is the average frontal areas of light $(\mathrm{X}=\mathrm{L})$ and heavy-duty $(\mathrm{X}=\mathrm{H})$ vehicles respectively, and with $\alpha$ being an empirical (dimensionless) constant, and $W$ the total width of the roadway. In the OML Highway model $A_{L}=4 \mathrm{~m}^{2}, A_{H}=16 \mathrm{~m}^{2}, \alpha=0.09$ and $\sigma_{z 0}=3.2 \mathrm{~m}$. The time constant is defined as:

$$
\tau=30 \cdot \exp \left(-\mathrm{u}_{*} / 0.273\right)+3
$$

where $u *$ is the friction velocity $\left(\mathrm{ms}^{-1}\right)$. From Equation (5) it follows that $\tau \approx 3$ seconds for large $u *$ while $\tau \approx 33$ seconds for values of $u *$ close to zero, thus Equation (5) expresses that TKE dissipates faster (slower) in strong (weak) wind conditions.

\section{DATA FROM NORDBYSLETTA, NORWAY}

This study uses data from a measurement campaign at Nordbysletta, Norway in 2002. Nordbysletta is situated at about $60^{\circ} \mathrm{N}$ and $11^{\circ} \mathrm{E}$ in the municipality of Lørenskog in a north-easterly direction from Oslo. The area consists of a relatively flat area containing a single (approximately) $850 \mathrm{~m}$ long segment of roadway with 4 separate lanes with traffic (Fig. 1). During morning hours the traffic is mainly headed towards Oslo, while in the afternoon and evening most of the traffic is directed in the opposite direction towards the town of Lillestrøm. The average peak traffic volume during morning and afternoon rush hours is around 3-4000 vehicles per hour. During the period 1 January 15 April 2002 a measurement campaign was conducted at the site. The set up of monitoring stations for air quality and meteorology during this period is shown in Figure 1.

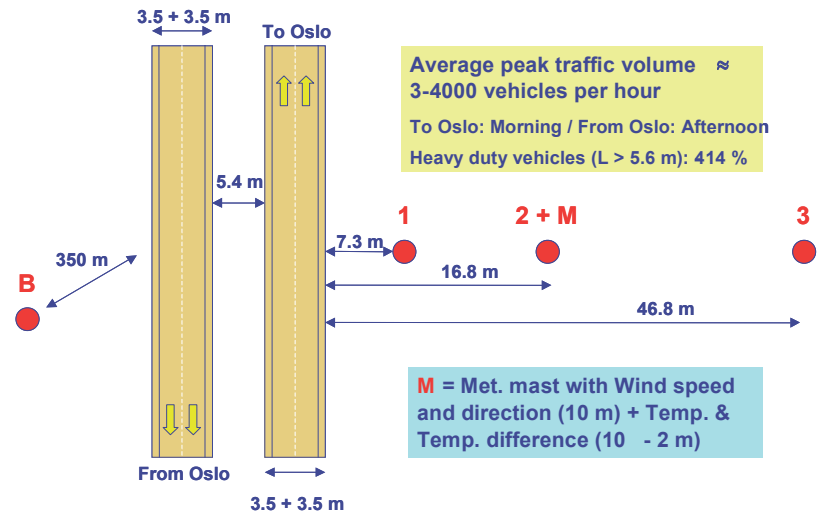

Figure 1. The Nordbysletta 4-lane roadway with air quality monitoring stations (1-3), meteorological station (M), and an air quality background station (B) used during the campaign. Direction is $240^{\circ}$ towards Oslo.

Stations 1-3 and B are air quality stations, measuring hourly average concentrations of $\mathrm{NO}_{\mathrm{x}}$ at a height of $3.5 \mathrm{~m}$ above ground, while station $\mathrm{M}$ is a meteorological mast coinciding with air quality station 2 . Stations $1-3$ and $\mathrm{M}$ are all situated on a line placed approximately midway between the end points of the roadway segment considered, while station $\mathrm{B}$ is a background station, placed around $350 \mathrm{~m}$ from the roadway, and in the opposite direction. The 4-lane roadway geometry and distances to the stations are indicated in the figure. The total width of the roadway is $\mathrm{W}=19.4$ $\mathrm{m}$. When the wind is headed towards stations 1-3 (1345 hours), the concentration at station B is subtracted from the concentrations at stations 1-3, to form net observed concentrations of $\mathrm{NO}_{\mathrm{x}}$ at stations 1-3 which can be compared with the model-calculated concentrations.

During the measurement campaign, traffic counting was performed locally on an hourly basis. For each hour, the number of light and heavy-duty vehicles (with length $>5.6 \mathrm{~m}$ ), were counted individually on each of the 4 lanes of the roadway. The heavy-duty vehicles constitute around $4-14 \%$ of the traffic volume on average. The average speed of the vehicles was approximately $90 \mathrm{kmhr}^{-1}$. Based on these data, hourly emissions of $\mathrm{NO}_{\mathrm{x}}$ were calculated using individual emission factors for the different vehicle classes primarily based on NILU's AirQUIS system (AirQUIS, 2005). Data recorded at station $M$ consist of hourly averaged values of wind speed and direction at $10 \mathrm{~m}$ above ground, temperature at $2 \mathrm{~m}$, and temperature difference measured between $10 \mathrm{~m}$ and $2 \mathrm{~m}$, the latter to indicate atmospheric stability. A separate meteorological pre-processor (WMPP) is used to calculate other derived meteorological parameters as described earlier. Momentum surface roughness at Nordbysletta is tentatively set to $0.25 \mathrm{~m}$ based on using the Davenport \& Wieringa site classification. 


\section{RESULTS}

A previous beta release of the WORM model was recently tested extensively on a number of datasets from the Nordic countries (Norway, Denmark and Finland), including data from Nordbysletta (Berger et al., 2008). In that study, only hours with wind speed $0.5 \mathrm{~ms}^{-1}$ or higher (at $10 \mathrm{~m}$ above ground) were used. Also, a minimum horizontal diffusivity $\sigma_{V}=0.5 \mathrm{~ms}^{-1}$ was applied in order to make the model fit the air quality observations for low wind speeds without overshooting. Horizontal and vertical diffusivities and mixing heights were calculated using COST 710 recommended equations (Fisher et al., 1998). Equations identical to the CAR-FMI model was used to describe the horizontal and vertical plume dispersion, but with Lagrangian time scales $T_{L y}$ and $T_{L z}$ set equal to $300 \mathrm{~s}$, for all atmospheric conditions. Minimum values for the Obukhov length and mixing height equal to $10 \mathrm{~m}$ were used, and the effective plume height $H_{\text {eff }}$ was set equal to $3 \mathrm{~m}$ above ground.

For the runs with the WORM model for Nordbysletta presented here, the same setup is used except for the following differences. Now hours with wind speed (at $10 \mathrm{~m}$ above ground) below $0.5 \mathrm{~ms}^{-1}$ is also used (minimum is $0.1 \mathrm{~ms}^{-1}$ during the 3.5 months period). Further, plume dispersion is calculated using the same procedure as in the OML Research Version model (Olesen et al., 2007, chapters 5.2-3), and in the OML Highway model for TPT (Berkowicz et al., 2007), as described by Equations (3)-(5) above, except that we still employ a fixed effective plume height equal to $3 \mathrm{~m}$ above ground. Minimum horizontal diffusivity $\sigma_{V}$ is now effectively set to $0.2 \mathrm{~ms}^{-1}$, since this is the value of $\sigma_{V}$ used in the horizontal meandering part of the OML Research Version model. The latter minimum value is also in agreement with recent observations of $\sigma_{V}$ as wind speed approaches zero as described in (Olesen et al., 2007). In the OML Highway model, the parameters $\alpha$ and $\sigma_{z O}$ (in Eq.s (3) and (4) above) have the values 0.09 and $3.2 \mathrm{~m}$ respectively. However, by using these values in the present version of WORM, it was found that the model concentrations became much too low compared with the air quality observations. Instead values of $\alpha$ and $\sigma_{z 0}$ equal to 0.04 and $1.0 \mathrm{~m}$ were found to give model concentrations more in line with the observations, and we have therefore used these values instead in the calculations presented here.

Figure 2 below shows a time series plot of observed and model calculated hourly average concentrations of $\mathrm{NO}_{\mathrm{x}}$ at station 2, calculated by the new version of WORM during the first half of January 2002. This was a period with (strongly) stable ( $\max \Delta T_{10-2 \mathrm{~m}}=+4.0 \mathrm{~K}$ ) and weak wind (minimum $U_{10 \mathrm{~m}}=0.1 \mathrm{~ms}^{-1}$ ) conditions. As can be seen from the figure, despite these extreme conditions, there is a reasonable good correspondence between observed and model calculated values during this period, except for some larger deviations. The latter must not come as a surprise, since clearly wind directions will be quite un-steady (and therefore uncertain) at hours with wind speed well below $1 \mathrm{~ms}^{-1}$.

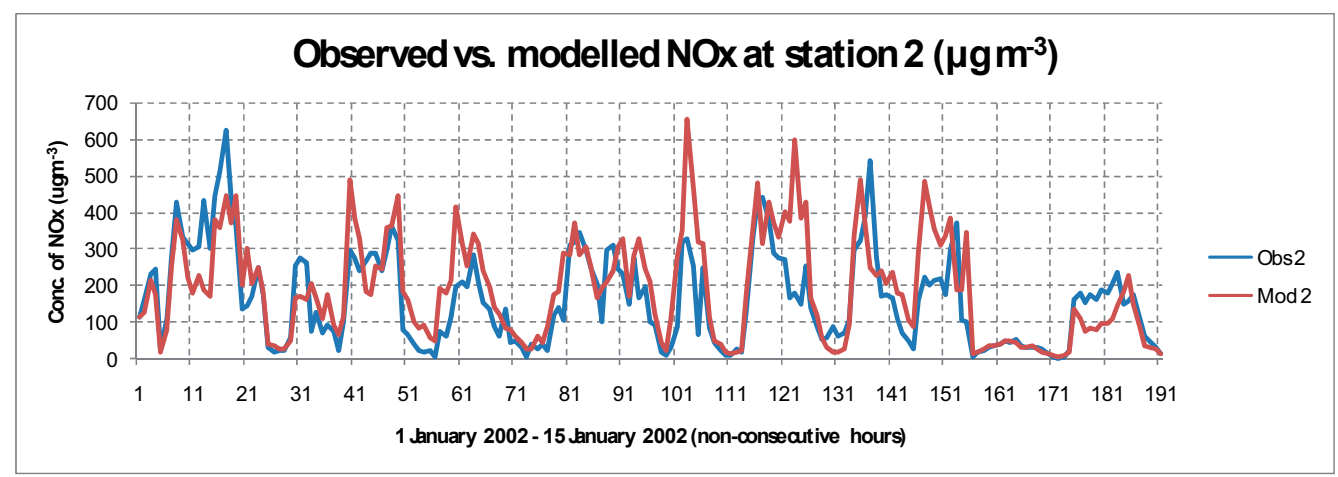

Figure 2. Time series plot of observed and model calculated concentrations of NOx at station 2 for the first half of January 2002. This was a period with (strongly) stable conditions $\left(\max \Delta \mathrm{T}_{10-2 \mathrm{~m}}=4.0\right.$ at hour 132) with low wind speed (min $\mathrm{U}_{10 \mathrm{~m}}=0.1 \mathrm{~ms}^{-1}$ at hour 40).

Figure 3 shows the observed (top row) and model calculated (bottom row) concentrations of $\mathrm{NO}_{\mathrm{x}}$ as a function of wind speed at $3 \mathrm{~m}$ above ground (left), wind direction (middle) and temperature difference $\left(\Delta T_{10-2 \mathrm{~m}}\right)$ (right) over the whole period (1345 hours). There is generally a good correspondence between the observed and model calculated values overall, except for a certain tendency of model underestimation. Similar results are obtained for stations 1 and 3 (not shown here). Observed vs. model calculated averages were $111 \mathrm{vs.} 95 \mu^{-3}$ at station $2 ; 147 \mathrm{vs}^{-1} 13 \mu \mathrm{gm}^{-3} \mathrm{at}^{-3}$

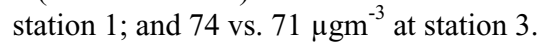

Scatter plots of model calculated vs. observed values at the three stations 1-3 are shown in Figure 4, showing a reasonable agreement between observed and model calculated values. Correlations are fairly high on all stations, being 0.84 at station $1 ; 0.81$ at station 2 ; and 0.78 at station 3 . 

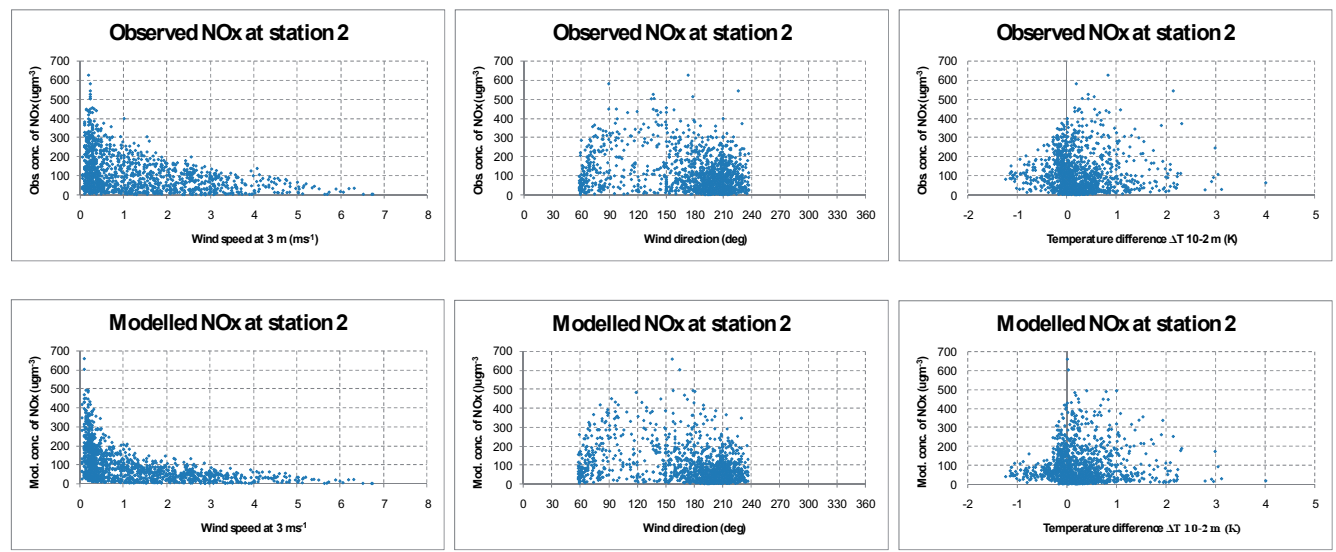

Figure 3. Observed (top row) and model calculated (bottom row) concentrations of $\mathrm{NO}_{\mathrm{x}}$ at station 2 as a function of wind speed at 3 $\mathrm{m}$ above ground (left), wind direction (middle) and temperature difference between 10 and $2 \mathrm{~m}$ indicating stability (right). All hourly values $(\mathrm{N}=1345)$ with wind direction towards stations 1-3 between 1 January 2002 and 15 April 2002 plotted.
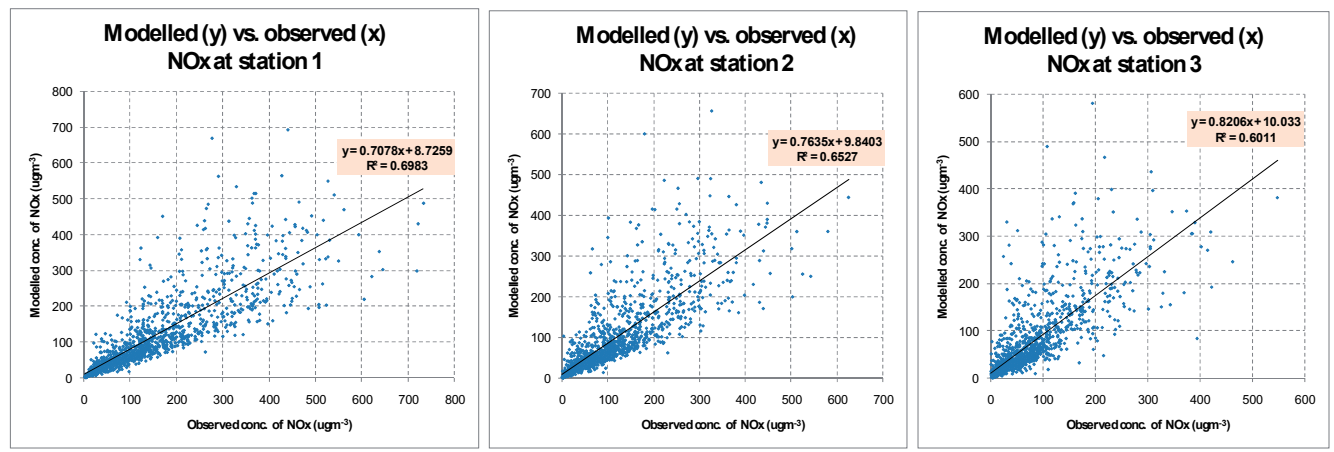

Figure 4. Scatter plot of observed (x) vs. model calculated (y) concentrations of NOx at station 1 (left), 2 (middle) and 3 (right). All hourly values $(\mathrm{N}=1345)$ with wind direction towards the stations 1-3 between 1 January 2002 and 15 April 2002 plotted.

\section{SUMMARY AND CONCLUSION}

A new version of the WORM model is presented. It incorporates an advanced (state-of-the-art) scheme for puff/plume modelling, applying dispersion functions for ambient atmospheric and traffic produced turbulence (TPT) as proposed in the recent OML Research Version and OML Highway models (Olesen et al., 2007; Berkowicz et al., 2007), the latter with somewhat adjusted parameters. Applying the new scheme using data from Nordbysletta in Norway during a 3-4 months period in the winter/spring of 2002, good agreement between observed and model calculated values of $\mathrm{NO}_{\mathrm{x}}$ was obtained, even in periods of (strongly) stable ( $\max \Delta T_{10-2 \mathrm{~m}}=+4.0 \mathrm{~K}$ ), and low-wind speed $\left(\min U_{10 \mathrm{~m}}=0.1 \mathrm{~ms}^{-1}\right)$ conditions.

Acknowledgement: I would like to thank Dyre Damman for his efficient efforts of preparing data and performing numerous calculations with the WORM model during his work at NILU in July 2008. Also, many thanks to Ruwim Berkowicz and Per Lofstrom at the National Environmental Research Institute (NERI) in Denmark, for answering many questions regarding roadway modelling in general, and details of the OML Highway model in particular. Finally, I would like to thank John Irwin for many interesting discussions about the WORM model development during his stay at NILU in November 2007.

\section{REFERENCES}

AirQUIS, 2005: NILU Air Quality Information System. Norwegian Institute for Air Research. http://www.nilu.no/airquis/

Berger, J., S.E. Walker, B. Denby, R. Berkowicz, P. Løfstrøm, M. Ketzel, J. Härkönen, J. Nikmo and A. Karppinen, 2008: Evaluation and inter-comparison of open road line source models currently in use in the Nordic countries. (this volume).

Berkowicz, R., P. Løfstrøm, M. Ketzel, S.S. Jensen and M. Hvidberg, 2007: OML Highway. Phase 1: Specifications for a Danish Highway Air Pollution Model. National Environmental Research Institute, University of Aarhus, Denmark. 62 pp. - NERI Technical Report No. 633. http://www.dmu.dk/Pub/FR633.pdf.

Fisher, B.E.A., J.J. Erbrink, S. Finardi, P. Jeannet, S. Joffre, M.G. Morselli, U. Pechinger, P. Seibert and D.J. Thomson, 1998: COST Action 710 - Final report. Harmonisation of the pre-processing of meteorological data for atmospheric dispersion models. EUR 18195. Luxembourg, Office for Official Publications of the European Communities, $431 \mathrm{pp}$. 
Härkönen, J., E. Valkonen, J. Kukkonen, E. Rantakrans, K. Lahtinen, A. Karppinen and L. Jalkanen, 1996: A model for the dispersion of pollution from a road network. Finnish Meteorological Institute, Publications on Air Quality 23, Helsinki.

Högström, U., 1996: Review of some basic characteristics of the atmospheric surface layer. Bound. Lay. Met., 78, 215-246.

Olesen, H.R., R. Berkowicz and P. Løfstrøm, 2007: OML: Review of model formulation. National Environmental Research Institute, University of Aarhus, Denmark. 130 pp. - NERI Technical Report No. 609, http://www.dmu.dk/Pub/FR609.

Kythe, P.K. and M.R. Schäferkotter, 2005: Handbook of Computational Methods for Integration. Chapman \& Hall/CRC, 598 pp.

Walker, S.E., 2007: Quantification of uncertainties associated with an integrated Gaussian line source model using ensembles. Proc. from the 11th Int. Conf. on Harmonisation within Atm. Dispersion Modelling for Regulatory Purposes, Cambridge, UK, July 2-5, 2007. http://www.cerc.co.uk/HARMO11/index.htm. 